\section{BMJ Open Respiratory Research}

\title{
Malignant pleural mesothelioma patients' experience by gender: findings from a cross-sectional UK- national questionnaire
}

\author{
Michaela Senek, ${ }^{1}$ Steve Robertson, ${ }^{1}$ Liz Darlison, ${ }^{2}$ Lorraine Creech, ${ }^{2}$ Angela Tod $^{1}$
}

To cite: Senek M, Robertson S, Darlison L, et al. Malignant pleural mesothelioma patients' experience by gender: findings from a cross-sectional UK-national questionnaire. BMJ Open Resp Res 2022;9:e001050. doi:10.1136/ bmjresp-2021-001050

- Additional supplemental material is published online only. To view, please visit the journal online (http://dx.doi. org/10.1136/bmjresp-2021001050).

Received 9 July 2021

Accepted 5 January 2022
Check for updates

(c) Author(s) (or their employer(s)) 2022. Re-use permitted under CC BY-NC. No commercial re-use. See rights and permissions. Published by BMJ.

${ }^{1}$ Division of Nursing and Midwifery, School of Health Sciences, The University of Sheffield, Sheffield, UK

${ }^{2}$ Mesothelioma UK, Leicester, UK

Correspondence to Dr Michaela Senek; m.senek@sheffield.ac.uk

\section{ABSTRACT}

Objectives Malignant mesothelioma is an aggressive malignancy of mesothelial surfaces, most commonly those of the pleura. The aim of this study was to understand, using a national questionnaire, the gendered care experiences of patients with malignant pleural mesothelioma (MPM)

Patients were asked about their experience of the diagnostic process, about information clarity, health care professionals' knowledge, general practitioner support and overall satisfaction with care received.

Setting Recruitment of patients was carried out in three UK countries (England, Wales and Scotland) via mesothelioma clinical nurse specialists.

Participants In total, 503 patients completed the questionnaire. 460 had MPM, the remainder had other types of mesothelioma. In accord with the study protocol, only the MPM patients were included in this study. Primary and secondary measures were: (1) time from symptom to diagnosis, (2) satisfaction with the diagnosis and treatment, and (3) quality of life and well-being. Results There were gender differences in time from symptom to diagnosis. The time from symptom to diagnosis was significantly longer for women than men (median $=152$ days vs men $=92$ days, $p=0.01$ ). Lack of a verified source of exposure to asbestos was a hindrance to private treatment access for women $(95 \%$ of those that access private treatment are men). Patients were five times more likely to be satisfied if they thought that the doctors knew enough about their condition $(\mathrm{OR}=4.4$, $\mathrm{p}=0.001$ ) and nearly three times more likely to be satisfied if information was presented in a sensitive way $(\mathrm{OR}=2.8, \mathrm{p}=0.01)$.

Conclusions This study has several implications for clinical practice. Our findings suggest that the diagnostic time in women might be reduced by reviewing diagnostic processes including occupational history taking, and by revising the occupational risk of mesothelioma categorisation.

\section{INTRODUCTION}

Malignant pleural mesothelioma (MPM) is a cancer caused by exposure to asbestos, a naturally occurring mineral. Globally, the incidence of MPM has risen steadily over the past decade. It is highest in the USA and UK,

\section{Key messages}

Are there gender differences in the malignant pleura mesothelioma patients' experience of the diagnosis and the treatment process?

- By reviewing diagnostic processes, including occupational history taking, and by reviewing the occupational risk of mesothelioma categorisation, gender differences may be reduced. This would benefit women, who are currently, based on our findings, disadvantaged.

- The article explains where in the care pathway the gender differences are most significant.

although Australia and Italy also rank highly in terms of the number of cases per capita. ${ }^{1}$ In the UK, there are approximately 2500 new cases registered in a year. ${ }^{2}$

In the UK, the source of exposure can be working in occupations where there is direct handling of asbestos, such as constructionrelated occupations, or from environmental exposure. The latter is mainly by exposure to low-levels of asbestos that is present in older buildings. In the UK, the Control of Asbestos Regulations 2012 recommend that asbestos should be maintained in-situ rather than removed (HSE 2020). Leaving asbestos in situ reduces the risk of fibres becoming airborne and can therefore help reduce asbestos exposure. However, this also means that the potential problem is deferred until a later date as buildings deteriorate over time.

The majority of cases of MPM arise in the pleura, this proportion being nearly 90\% in the UK, with the bulk of the remaining $7 \%-10 \%$ arising in the peritoneum. ${ }^{3} \mathrm{~A}$ geographical analysis of MPM deaths in the UK between 1968 and 2001 showed a higher prevalence in industrial areas, such as those with a preponderance of shipyards. An analysis by occupation suggested that asbestos 
exposure in the construction industry accounted for a substantial proportion of MPM deaths. ${ }^{4}$

In the UK, in $2017,83 \%$ of all cases were in men and $17 \%$ in women. ${ }^{5}$ The prognosis is poor with an overall survival rate of $7 \%$ after 5 years although survival rates are higher in women than men. ${ }^{6}$ These gender differences are thought to result from men's greater occupational exposure to asbestos (direct handling compared with women's environmental exposure) and perhaps to some physiological protection afforded to women against the disease by circulating hormones. ${ }^{7}$ Further studies have also shown that women who are diagnosed before the age of 45 have better survival rates than women of the same age who have been diagnosed later in life. ${ }^{7}$

It follows that timely identification is crucial. ${ }^{8}$ At the time of diagnosis, patients most commonly present with symptoms such as breathlessness and chest pain. ${ }^{9}$ Patients' experience of diagnosis, access to tests, general practitioner (GP) support and subsequent treatment differs. ${ }^{10}$ A national audit study from 2015 in England and Wales of 8740 MPM cases showed that just under half $(47 \%)$ were being referred to a specialist from their GP, $14 \%$ of patients were referred following an emergency admission to hospital and 7\% after an A\&E attendance, with a further $21 \%$ being referred from a consultant in a non-respiratory specialty. ${ }^{11}$

A recently published study by Senek and Steve Robertson found variations in time from symptom to diagnosis. It showed that it takes longer for women to be diagnosed with MPM than men. ${ }^{12}$ It also suggested that most of the asbestos exposure in women was by means of indirect occupational exposure in ageing buildings such as schools, hospitals and shops. ${ }^{12}$ These occupations are traditionally viewed as having a low risk of exposure to asbestos. The emphasis on high-risk occupations, such as construction the industry, may have masked the occupational risk to individuals who experience a low-level exposure in deteriorating buildings. This emphasis may affect the duration of the diagnostic process as, for example, the taking of patients' histories will depend in part on health professionals' understanding of occupational risk. The study recommended that further research is needed into the real-time risk of such exposure, as well as raised awareness among health professionals. ${ }^{12}$

Other studies that have explored the care pathway, including a systematic review, have found that receiving the diagnosis is psychologically difficult and challenging for patients. ${ }^{9}$ Due to poor prognosis and limited treatment options, many are left with a feeling of hopelessness and depression. ${ }^{13}$ A recent qualitative study by Taylor $e t$ $a l$, produced a set of recommendations for healthcare professionals to improve patient experience of diagnosis. ${ }^{10}$ The main findings highlighted the importance of honesty and timeliness in communication. The main deficiencies were linked to a lack of suitable environment, insufficient time allocation and a lack of appropriate training. In this study, we will explore patients' experience of the care pathway based on self-reported outcomes from the national Mesothelioma, Outcomes, Research and Experience (MORE) survey as well as exploring gender differences (see online supplemental appendix 1).

\section{METHODS}

\section{Source of data}

Recruitment and data collection were carried out in May 2019 by the 25 mesothelioma clinical nurse specialists across the UK who shared the questionnaire with MPM patients via a mailing list and in face-to-face clinics. This ensured that at least $70 \%$ of all UK patients with MPM at that time were invited to take part in the study. In addition, a link to the questionnaire was shared via social networking groups and the Mesothelioma UK website. Respondents were asked about their experiences of the diagnostic process, time from symptom to diagnosis and treatment satisfaction. The questions concerned:

- Clarity (whether the information they received was understandable).

- Sensitivity (whether it was given in a sensitive way).

- Healthcare professionals' knowledge (whether the doctors knew enough about the condition).

- GP support (whether enough support was received from your GP).

- Overall satisfaction with care received.

In addition, there were questions about treatment experience which mainly concerned symptom management. In addition to these questions a quality of life (QoL) validated tool (EQ5D) was included.

The participants completed the survey remotely online. The medical sections of the survey were then validated by a specialist nurse. Next, the data were anonymised and shared with the University of Sheffield research team via a double-password-encrypted file.

\section{Patient and public involvement}

As this was a secondary data analysis, we could not manipulate the study design, data collection processes and questionnaire design. However, the analysis was informed by discussions and interviews with patients in the Gendered Experience of Mesothelioma Study. ${ }^{14}$ The analysis was also informed by the conversations and analysis of the Asbestos Support Group HASAG data set, which was published in $2020{ }^{12}$

\section{Data sharing agreement}

A data sharing agreement was set up between Mesothelioma UK and the University of Sheffield. Mesothelioma UK shared the double-passwordencrypted data set via a password-protected server that could only be accessed by the research team.

\section{Data analysis}

Statistical analysis explored (1) gender differences in the population of MPM patients and (2) the relationship 
between type of exposure, occupational categories and time from symptom to diagnosis between genders. Missing gender data was reported as 'missing'. Gender differences were also explored in relation to satisfaction with the diagnostic and treatment process as well as its relationship with QoL and symptom management. Statistical analysis was carried out in SPSS V.26. The ShapiroWilk test was used to assess the normality of data. For data where normal distribution could not be assumed, descriptive statistics were expressed as medians and IQRs. The Mann-Whitney U test was used to compare nonparametric data. A probability value below $0.05(\mathrm{p}<0.05)$ was considered to be statistically significant. Logistic regression was carried out to determine factors that affect satisfaction with the diagnosis.

\section{RESULTS}

In the MORE data set, there were 503 pleural and peritoneal mesothelioma cases, out of which were 460 MPM cases that were included in this analysis. The sample included patients from three UK countries: England 89.1\% $(\mathrm{n}=410)$, Scotland $5.7 \%(\mathrm{n}=26)$ and Wales $2.4 \%$ $(\mathrm{n}=11)$. There were 13 cases $(2.8 \%)$ that did not provide their location. There were $376(81.7 \%)$ men and 81 $(17.6 \%)$ women and three cases that did not report gender. The gender distribution was consistent with the National Mesothelioma Audit for the period 2016-2018, in which $82 \%$ of patients were male and $18 \%$ were female (Royal College of Physicians, 2020). There was a significantly higher percentage of women below the age of 65 (25.9\% compared with men $18.1 \%), \mathrm{p}=0.05$. Table 1 summarises patient's age by gender.

The subtypes of MPM were epithelioid $(78.9 \%, \mathrm{n}=362)$, mixed biphasic $(8.5 \%, \mathrm{n}=39)$, unspecified $(7 \%, \mathrm{n}=32)$, sarcomatoid $(5.7 \%, \mathrm{n}=26)$. The majority of the patients in the data set $(47 \%)$ were categorised by a healthcare professional as being at a tumour stage that was unsuitable for surgery, $43.9 \%$ were categorised as suitable for surgery, and $9.1 \%$ were not staged. More men than women were categorised as suitable for surgery $(45.4 \%$ vs $37 \%)$. Surgery is not a standard form of treatment; however, the study participants were assessed as either suitable or not suitable for a surgery. The assessment took into account whether disease is confined (suggesting earlier stage),

\begin{tabular}{lll}
\hline Table 1 & Patients' age by gender & \\
\hline Age & Men & Women \\
\hline 50 or less & $\mathrm{N}=3(0.8 \%)$ & $\mathrm{N}=3(3.7 \%)$ \\
$51-55$ & $5(1.3 \%)$ & $\mathrm{N}=3(3.7 \%)$ \\
$56-60$ & $\mathrm{~N}=15(4 \%)$ & $\mathrm{N}=3(3.7 \%)$ \\
$61-65$ & $\mathrm{~N}=45(12 \%)$ & $\mathrm{N}=12(14.8 \%)$ \\
& ${ }^{*} 18.1 \% \leq 65$ & ${ }^{*} 25.9 \% \geq 65$ \\
$66-70$ & $\mathrm{~N}=77(20.5 \%)$ & $\mathrm{N}=14(17.3 \%)$ \\
$70+$ & $\mathrm{N}=230(61.3 \%)$ & $\mathrm{N}=46(56.8 \%)$ \\
\hline
\end{tabular}

subtype, patients' comorbidities and general health and fitness.

\section{Satisfaction throughout the diagnostic process}

In the sample, $80 \%$ of patients reported that they were satisfied with the diagnostic process compared with $20 \%$ $(n=92)$ that reported that they were dissatisfied (table 2). Patients were also asked about how understandable, knowledgeable, and sensitive the diagnostic process was. They were also asked about perceived GP support available as well as overall satisfaction with the process and the healthcare professionals. The highest dissatisfaction rate (55.9\%) was with patients' experience with their GP. This was followed by more than one in three $(38.3 \%)$ stating that their diagnosis was not presented in an understandable way.

There were no statistically significant differences between men and women in terms of satisfaction and overall experience throughout the diagnostic process (table 2).

\section{Factors that correlate with the level of satisfaction with the diagnosis}

There were relatively low levels of correlation between Health Professionals' level of knowledge $(r=0.377)$ and their sensitivity $(r=0.269)$, the overall satisfaction of the diagnostic process and lower levels between understandability $(\mathrm{r}=0.217)$, multi-disciplinary team case review $(\mathrm{r}=0.161)$ and GP support $(\mathrm{r}=0.1)$.

A logistic regression analysis showed that the factor having the biggest impact on satisfaction throughout the diagnostic process was the perceived level of HPs' knowledge, ${ }^{1} \mathrm{p}=0.001, \mathrm{OR}=4.43$. The second most impactful factor was whether patients perceived that the diagnosis was delivered in a sensitive way $((1), \mathrm{p}=0.01, \mathrm{OR}=2.81)$ followed by the number of times that patients had to see their GP ((1), p=0.039, OR=2.166). Respondents were nearly 4.5 times more likely to be satisfied if they perceived that health professionals were knowledgeable about their conditions $(\mathrm{OR}=4.4)$ and nearly three times more likely to be satisfied if the diagnosis was delivered in a sensitive way $(\mathrm{OR}=2.8)$. The factors that did not significantly impact patient satisfaction were whether the diagnosis was understandable $(\mathrm{p}=0.69)$ or whether a multidisciplinary team had reviewed their case $(p=0.76)$

\section{Time from symptom to diagnosis}

Time from first symptom to diagnosis also differed between patients who were satisfied vs those not satisfied with the diagnostic process. Those patients that reported feeling overall satisfaction with health professionals during the diagnostic process also reported a significantly shorter time from first symptom to diagnosis (median $=91, \mathrm{IQR}=61-92$ days vs median $=122$ days, $\mathrm{IQR}=91-123, \mathrm{p}=0.05)$. 
Table 2 Summary table of the diagnostic experience

\begin{tabular}{|c|c|c|c|c|}
\hline & \multirow[b]{2}{*}{ No } & \multicolumn{3}{|c|}{ MPM diagnostic process } \\
\hline & & Yes & $X^{2}, p$ value & Total \\
\hline \multirow{3}{*}{$\begin{array}{l}\text { Was the explanation of the } \\
\text { mesothelioma diagnosis } \\
\text { understandable }\end{array}$} & 176 & 283 & \multirow[t]{3}{*}{$(1)=1.548,0.257$} & \multirow[t]{3}{*}{459} \\
\hline & $38.30 \%$ & \multirow[t]{2}{*}{$61.70 \%$} & & \\
\hline & (44.4\% women, $37.1 \%$ men) & & & \\
\hline $\begin{array}{l}\text { Was the explanation given in } \\
\text { sensitive way }\end{array}$ & 126 & 332 & $(1)=0.638,0.681$ & 458 \\
\hline \multirow[t]{2}{*}{ Sensitivity } & $27.50 \%$ & \multirow[t]{2}{*}{$72.50 \%$} & & \\
\hline & (29.6\% women, $26.7 \%$ men) & & & \\
\hline \multirow{3}{*}{$\begin{array}{l}\text { Were you told that a } \\
\text { multidisciplinary team had reviewed } \\
\text { your case. }\end{array}$} & 106 & 250 & \multirow[t]{3}{*}{$(1)=1.498,0.148$} & \multirow[t]{3}{*}{356} \\
\hline & $29.80 \%$ & \multirow[t]{2}{*}{$70.20 \%$} & & \\
\hline & (32.7\% women, $22.3 \%$ men) & & & \\
\hline $\begin{array}{l}\text { Did healthcare professionals have } \\
\text { sufficient knowledge and know } \\
\text { enough about your condition }\end{array}$ & 115 & 344 & $(1)=0.786,0.778$ & 459 \\
\hline \multirow[t]{2}{*}{ Knowledge } & $25.10 \%$ & \multirow[t]{2}{*}{$74.90 \%$} & & \\
\hline & (26.3\% women, $24.7 \%$ men) & & & \\
\hline $\begin{array}{l}\text { Did you receive good support } \\
\text { from your GP in relation to your } \\
\text { diagnosis }\end{array}$ & 252 & 199 & $(1)=0.675,0.727$ & 451 \\
\hline \multirow[t]{2}{*}{ GP support } & $55.90 \%$ & \multirow[t]{2}{*}{$44.10 \%$} & & \\
\hline & (54.8\% women, $55.1 \%)$ & & & \\
\hline $\begin{array}{l}\text { Were you overall satisfied with } \\
\text { healthcare professionals during } \\
\text { your diagnosis }\end{array}$ & 92 & 364 & $(1)=0.845,0.857$ & 456 \\
\hline \multirow[t]{2}{*}{ Overall satisfaction } & $20.20 \%$ & \multirow[t]{2}{*}{$79.80 \%$} & & \\
\hline & (21.5\% women and $19.8 \%$ men) & & & \\
\hline
\end{tabular}

GP, general practitioner; MPM, malignant pleural mesothelioma.

\section{Time from symptom to diagnosis by occupation and gender} Respondents were asked the following questions relating to their asbestos exposure: (1) From your memory were you ever exposed to asbestos? In the sample, $76.4 \%$ of men responded 'Yes, through my work', compared with only $28.9 \%$ of women and, (2) 'If exposed at work, what was your occupation at the time'. Occupation and source of exposure were then categorised into direct handling versus environmental exposure occupations. Builders, electricians, carpenters, laggers and plumbers were combined into Direct handling category (direct handling of asbestos at work) and teachers, doctors, nurses', administrative staff and secretarial staff were combined into Working Environment category.

Furthermore, $18.6 \%$ of women compared with $3.9 \%$ of men reported that they had been exposed via their partners, for instance by washing their clothes. This has been reported in previous literature. ${ }^{6}$ In our sample, the time from symptom to diagnosis was significantly longer for women than men (median=152 days vs men=92 days, $\mathrm{p}=0.01$ ).

There were no women in the occupational categories where there is direct handling of asbestos, therefore we could not directly compare the time from symptom to diagnosis in this category. However, a comparison of the time from symptom to diagnosis in the did not know where they had been exposed/no occupation category between women and men showed that it took significantly longer for women to be diagnosed (151 days) compared with men (91 days; IQR=55-80, p=0.05) (see table 3).

The women who reported knowing that they had been exposed at work had mainly been exposed via their working environment as opposed to via direct handling of asbestos. The way that the question was phrased may be problematic to the analysis of this data because they were only asked to list their occupation if they knew/had proven that they had been exposed at work. This question may be problematic because in the cases of environmental exposure it is more difficult to know/prove that this was the case. Therefore, in future cases, occupation data should be collected from all patients.

\section{Satisfaction throughout the care pathway}

In the patients questioned, the majority $(59.8 \%, \mathrm{n}=275)$ travelled to a different hospital for treatment from the 
Table 3 Occupational category and time from symptom to diagnosis

\begin{tabular}{llll}
\hline $\begin{array}{l}\text { Occupation/source of exposure, time from } \\
\text { symptom to diagnosis (median, days) }\end{array}$ & Men & Women & P value \\
\hline $\begin{array}{l}\text { Construction (builder, electrician, plumber, } \\
\text { carpenter, lagger) }\end{array}$ & $\begin{array}{l}49.6 \%,(\mathrm{~N}=188), 92 \text { days, } \\
\mathrm{IQR}=50-81\end{array}$ & $\begin{array}{l}\text { There were no women in } \\
\text { this category. }\end{array}$ & Not applicable \\
Work environment (teacher, doctor, nurse, & $\begin{array}{l}2.6 \%,(\mathrm{~N}=10), 97 \text { days, } \\
\text { secretarial, admin) }\end{array}$ & $\begin{array}{l}17.3 \%,(\mathrm{~N}=14), 396 \text { days, } \\
\mathrm{IQR}=35-90\end{array}$ & 0.47 \\
No occupation listed because assumed/could & $24 \%(\mathrm{~N}=91), 90$ days, & $67.9 \%,(\mathrm{~N}=55), 151$ days, & 0.076 \\
not prove that was exposed at work & $\mathrm{IQR}=50-77.5$ & $\mathrm{IQR}=60-80$ & 0.75 \\
Other & $23.7 \%,(\mathrm{~N}=90), 92$ days, & $14.8 \%,(\mathrm{~N}=12), 169$ days, & $0.05^{\star}$ \\
& $\mathrm{IQR}=50.75-85$ & $(\mathrm{IQR}=80-95.25)$ & \\
\hline
\end{tabular}

*Significant.

one in which they had been diagnosed, while $38.9 \%$ $(n=179)$ of patients were both diagnosed and treated in the same hospital. Out of the patients that were referred to another hospital, 28\% $(n=129)$ received all their care in that same hospital, while $17.2 \% \quad(n=79)$ shared care between hospitals. The majority of the patients $(94.6 \%)$ reported that the appointments with the doctor and/or medical team were frequent enough. In terms of outpatient appointments, $83 \%$ of patients thought that it was easy/fairly easy to make an appointment, $4 \%$ found it difficult and $13 \%$ did not know/could not remember.

\section{Private treatment by gender expected/received}

More than one in five patients $(23.3 \%, \mathrm{n}=107)$ reported that they had, or will be, expected to pay for private treatment. Out of the 107 (23.3\%), that reported this, only $11 \%$ were women $(n=12)$.

\section{Private treatment by gender received}

Nearly $62.6 \%(n=67)$ reported that they had already had their non-National Health Service (NHS)-funded treatment costs covered as part of their legal claim. Out of the 67 cases $(62.6 \%)$ that had their non-NHS funded treatment costs covered, the majority were men $(95 \%, n=64)$. Only $3.7 \%(n=3)$ of women reported that they already had their additional private treatment costs covered as part of their legal claim compared with $95 \%(n=64)$ of men $(p=0.01)$.

\section{Treatment type and QoL}

In this patient cohort, $75.9 \%$ had chemotherapy, $16.5 \%$ had surgery, $10.9 \%$ immunotherapy, $9.1 \%$ had radiotherapy, $8.5 \%$ had no treatment and $1.8 \%$ had targeted therapy. A Quality-of-Life score was assessed using the 0-100 EuroQoL-5D instruments scale. Patients that had surgery reported the highest QoL score (71.6). Selfreported QoL for those who only had chemotherapy was 67.2, radiotherapy $\mathrm{QoL}=65$, immunotherapy $\mathrm{QoL}=69$, no treatment $\mathrm{QoL}=61.8$. However, a comparison by gender showed different QoL by treatment scores (see table 4)

Respondents were asked to rate their overall QoL and well-being using the EQ5D scale. QoL score was only slightly higher in the group that reported satisfaction with overall treatment (IQR 70 vs 68, $\mathrm{p}=0.2)$. The median $\mathrm{QoL}$ score was significantly higher among women (women $\mathrm{QoL}=74$, men $\mathrm{QoL}=70, \mathrm{p}=0.04$.).

Satisfaction with the treatment most strongly correlated with the perception that HPs have sufficient knowledge of their condition $(\mathrm{r}=0.42)$, management of fatigue $(\mathrm{r}=0.28)$, pain management $(\mathrm{r}=0.24)$, cough management (0.23), and breathlessness $(\mathrm{r}=0.22)$. All correlations were significant $(\mathrm{p}<0.01)$ (see table 5$)$.

\section{Mental health}

Respondents were also asked to rate their level of anxiety and depression, as either not, slightly, moderately, extremely or severely depressed. There were no differences between men and women $(81.4 \%$ women vs $81.2 \%$ of men) that had no or slight problem with depression and anxiety. The proportion of moderately depressed was also similar ( $15.8 \%$ of men vs $16 \%$ of women). There were proportionately more men (2.4\% vs $1.2 \%$ women) that reported extreme to severe anxiety and depression levels.

\section{DISCUSSION}

This study provides new insights into MPM patients' experiences in relation to gender, satisfaction with diagnosis

Table 4 Quality of life (QoL) score by treatment type received

\begin{tabular}{llll}
\hline $\begin{array}{l}\text { Treatment } \\
\text { received }\end{array}$ & $\begin{array}{l}\text { Men } \\
\text { Median, } \\
\text { IQR QoL } \\
\text { Score }\end{array}$ & $\begin{array}{l}\text { Women } \\
\text { median, } \\
\text { IQR QoL } \\
\text { Score }\end{array}$ & $\begin{array}{l}\text { Satisfaction } \\
\text { rate with } \\
\text { treatment }\end{array}$ \\
\hline Surgery & 75 & 77.5 & $83.9 \%$ \\
Chemotherapy & 70 & 70 & $86.9 \%$ \\
Radiotherapy & 60 & 68.5 & $81.1 \%$ \\
Immunotherapy & 75 & 70 & $92.7 \%$ \\
Targeted therapy & 67.8 & 82.5 & $75 \%$ \\
None & 60 & 67 & $85 \%$ \\
\hline
\end{tabular}


Table 5 Patients' experience of the treatment

\begin{tabular}{|c|c|c|c|}
\hline \multirow[b]{2}{*}{ Treatment-related question } & \multicolumn{3}{|c|}{ MPM treatment process } \\
\hline & Yes (\%) & No (\%) & Total \\
\hline $\begin{array}{l}\text { Satisfaction with treatment (yes/no) } \\
\text { Overall have all the professionals involved in your } \\
\text { treatment worked well together to provide the best } \\
\text { possible care? }\end{array}$ & $\begin{array}{l}(\mathrm{n}=380) 83.7 \% \\
\text { Women }=85.9 \% \\
\text { Men=83.2\% }\end{array}$ & $\begin{array}{l}(\mathrm{n}=74) 16.3 \% \\
\text { Women }=14.1 \% \\
\text { Men }=16.8 \%\end{array}$ & $\begin{array}{l}\text { Total }=460 \\
\mathrm{~N}=4 \text { chose not to say }\end{array}$ \\
\hline $\begin{array}{l}\text { Perception that health professionals had sufficient } \\
\text { knowledge (yes/no) } \\
\text { Do you think that the doctors treating mesothelioma } \\
\text { knew enough about the condition and treatment?* }\end{array}$ & $\begin{array}{l}(\mathrm{n}=396) 86.5 \% \\
\text { Women }=84.4 \% \\
\text { Men=85.7\% }\end{array}$ & $\begin{array}{l}(\mathrm{n}=62) 13.5 \% \\
\text { Women }=15.6 \% \\
\text { Men }=14.3 \%\end{array}$ & $\begin{array}{l}\text { Total }=458 \\
\mathrm{~N}=2 \text { chose not to say }\end{array}$ \\
\hline $\begin{array}{l}\text { Breathlessness controlled (yes/no)* } \\
\text { Did hospital doctors and nurses do everything they } \\
\text { could to help control any breathlessness? }\end{array}$ & $\begin{array}{l}(\mathrm{n}=209) 68.5 \% \\
\text { Women }=71 \% \\
\text { Men=67.2\% }\end{array}$ & $\begin{array}{l}(n=96) 38.5 \% \\
\text { Women }=29 \% \\
\text { Men }=32.8 \%\end{array}$ & $\begin{array}{l}\text { Total }=305 \\
\mathrm{~N}=153 \text { did not have this } \\
\text { symptom }\end{array}$ \\
\hline $\begin{array}{l}\text { Fatigue controlled (yes/no) } \\
\text { Did hospital doctors and nurses do everything they } \\
\text { could to help control any fatigue? }\end{array}$ & $\begin{array}{l}(\mathrm{n}=154) 53.1 \% \\
\text { Women }=49.2 \% \\
\text { Men=53.9\% }\end{array}$ & $\begin{array}{l}(\mathrm{n}=136) 46.9 \% \\
\text { Women }=50.8 \% \\
\text { Men }=46.1 \%\end{array}$ & $\begin{array}{l}\text { Total }=290 \\
\mathrm{~N}=168 \text { did not have this } \\
\text { symptom }\end{array}$ \\
\hline $\begin{array}{l}\text { Coughing controlled* } \\
\text { Did hospital doctors and nurses do everything they } \\
\text { could to help control any coughing? }\end{array}$ & $\begin{array}{l}(n=103) 53.3 \% \\
\text { Women }=52.8 \% \\
\text { Men }=52.4 \%\end{array}$ & $\begin{array}{l}(\mathrm{n}=94) 47.7 \% \\
\text { Women }=47.2 \% \\
\text { Men }=47.6 \%\end{array}$ & $\begin{array}{l}\text { Total }=197 \\
\mathrm{~N}=261 \text { did not have this } \\
\text { symptom }\end{array}$ \\
\hline $\begin{array}{l}\text { Pain controlled* } \\
\text { Did hospital doctors and nurses do everything they } \\
\text { could to help control any pain? }\end{array}$ & $\begin{array}{l}(\mathrm{n}=218) 77.6 \% \\
\text { Women }=71.1 \% \\
\text { Men }=78.8 \%\end{array}$ & $\begin{array}{l}(\mathrm{n}=63) 22.4 \% \\
\text { Women }=28.9 \% \\
\text { Men }=21.1 \%\end{array}$ & $\begin{array}{l}281 \\
\mathrm{~N}=177 \text { did not have this } \\
\text { symptom }\end{array}$ \\
\hline
\end{tabular}

${ }^{*}$ None of the treatment processes were statistically significantly different between men and women.

MPM, malignant pleural mesothelioma.

and treatment, time from symptom onset to diagnosis, source of exposure/occupation and QoL.

Our study population contained proportionally more men than women with MPM. However, the proportion of younger women was greater than that of younger men (26\% of women compared with $18.1 \%$ of men were 65 years or younger). This finding corresponds to the national figures. ${ }^{5}$

The results suggest that women were disadvantaged during the time of diagnosis, which was significantly longer compared with men. This echoes previous findings of a study based on a cohort of MPM patients in South of England ${ }^{12}$ which showed that it took longer for women to be diagnosed. In MPM, men are often diagnosed sooner, possibly because the disease is more common in men and because there is a higher awareness among healthcare professionals of the risk of mesothelioma for those in direct handling occupations. In our sample, there were no women that were in the direct handling occupational category. Aligning with the findings in Senek and Steve Robertson, in our sample of working women, the occupational risk was more likely to be linked to indirect exposure in a contaminated work environment, rather than to the direct handling of asbestos. Occupational differences between men and women with MPM thus have implications for healthcare staff. To improve the diagnosis of MPM, insight is needed into how occupational histories are taken in healthcare settings. Furthermore, patients who experience a diagnostic delay may require additional support in coming to terms with the diagnosis and the fact that it has been delayed. Ball et al have shown that, if diagnostic delay is not addressed appropriately, it can have detrimental psychological effects on patients. ${ }^{9}$

Most patients $(80 \%)$ reported that they were satisfied with the diagnostic process. However, those that were dissatisfied had a significantly longer time from symptom to diagnosis. This suggests that the time it takes to be diagnosed leads to dissatisfaction. During the diagnostic period, the highest proportion of dissatisfaction (55.7\%) was with support received from their GP. However, patients were most likely to be satisfied if the diagnosis was delivered sensitively $(\mathrm{OR}=4.4, \mathrm{p}=0.001)$ and if they felt that the HP was knowledgeable $(\mathrm{OR}=2.8, \mathrm{p}=0.01)$. A high proportion of patients also reported that their diagnosis was not understandable $(38.3 \%)$ but this factor was not as important as the sensitivity and knowledge of HPs.

There is a need for training in taking extended asbestos exposure history and occupational exposure among HPs. A comprehensive history is essential to the diagnostic process as HPs are unlikely to suspect the disease unless a patient describes a job where asbestos exposure may have occurred. Mesothelioma is a rare disease with similar symptoms to more common and less severe conditions. At present, it is sometimes confused for a different illness or another type of cancer, such as pneumonia or lung cancer.

The highest QoL score was among those patients that had surgery as part of their treatment. However, this may be due to the overall selection bias, as fitter patients are likely to have a higher QoL prior to treatment. Therefore, 
their overall QoL score may have made them eligible for surgery in the first place. Women reported a higher overall QoL score.

In our sample, women were less likely to have additional private treatment. This may be due to the costs involved and because they are significantly less likely to have the costs of additional non-NHS-funded treatment covered by a compensation settlement. So far, no data has been collected at a national level on intention to seek legal advice, and actions subsequently taken, to compare differences between men and women. ${ }^{15}$ A previous study by Senek and Steve Robertson, based on mesothelioma cases from South of England, showed that women were less likely to apply for compensation. ${ }^{12}$ This may be explained by the higher awareness of the association between some occupational categories and asbestos-related diseases. In our study, women's occupational exposure was more often linked to indirect exposure in the work environment than to the direct handling of asbestos. These occupations are still classified as 'lowrisk', (rightly or wrongly) resulting in fewer precedents for taking legal action.

Unlike Rake et al, this study did not find that the occupational risk in women was concentrated in industrial settings but found occupational risk in office-based work environments. ${ }^{6}$ It suggests that a long term, low-level exposure may be causing an increase in mesothelioma cases among people working in occupations that have previously not been noted as particularly risky. This is in line with previous research indicating that mesothelioma can develop from long-term exposure to low concentrations of asbestos fibres in the air. ${ }^{16}$ At present, a value of $0.01 \mathrm{fibres} / \mathrm{mL}$ is taken as the 'clearance indicator' threshold, and a site should not normally be regarded as fit for reoccupation until the asbestos in air measurements are below this level. It is noteworthy that this value is 10 times higher than that which countries like Germany, France and the Netherlands permit. Therefore, the UK may currently be underestimating the risk of low-level exposure. This theory is supported by the high proportion of mesothelioma cases among patients that had been employed in so called low-risk occupations and would suggest that long-term, low-level exposure is a concern. Therefore, more emphasis is required on the risk associated with long-term, low-level indirect exposure resulting from working in asbestos-contaminated buildings. This recognition would be of particular benefit to women.

\section{Strengths and limitations}

This is the first study to explore the experience of MPM patients by gender in three UK countries. The study participants were from all but one of the four UK countries (there were no Northern Ireland cases). The study population can be considered to represent patients with MPM across most of the UK and results can be extrapolated at national level. The data, however, did not include information on potential exposure to asbestos in childhood, previous medical history, exact geographical location and whether patients' partners had been working in a high-risk area. Such data could potentially identify other sources of exposure given that certain geographical locations and exposure through a partner are known sources. The data set did not include any information on patients' disease progression or survival rates, which would have been additional indicators of quality of care received. Furthermore, in our data set, the proportion of respondents that had active treatment was higher than the proportion reported in the National Mesothelioma Audit. This is a potential limitation of the study. It may be that, unknowingly, a group biased towards those of better performance status and less advanced disease was sampled.

\section{Implications for practice}

This study has several implications for clinical practice, in particular regarding diagnostic processes and patient support. In the study, it took longer for women to be diagnosed than for men. The reason for this gender-based delay in diagnosis is unknown. In MPM, men are often diagnosed quicker, possibly because it is more common in men and the fact that healthcare professionals may take a more detailed or accurate occupational history for men than for women due to the varying awareness of risk of mesothelioma according to occupation and/ or gender. Occupational differences between men and women are not merely a legal issue, but also have implications for healthcare staff. To improve the diagnosis of MPM, it could be beneficial to review the diagnostic process in order to determine the cause of delay, particularly for women.

The HP's level of sensitivity and knowledge were significant determinants of patient satisfaction. Consideration could therefore be given as to how this can be improved for the large proportion of patients that felt that this was lacking. This further highlights the importance of early referral and signposting to services that have more expert knowledge and experience in treating and caring for those with mesothelioma.

HPs need to be more alert to a diagnosis of MPM in both men and women who have no history of direct exposure to asbestos. To address the delays and gender differences in the care pathway, it is important that HPs are better informed regarding the age and types of exposure in women. However, for unexplained reasons women in this category have a longer symptom to diagnosis period than men. Awareness around the importance of communication skills and better knowledge among HPs could be further improved by all stakeholders, including national societies and cancer charities. In addition, the delayed diagnosis and prolonged care pathway could be addressed in at least two ways: first, by means of implementation of Getting it Right the First Time Cancer recommendations and, second, through a dedicated suspected-mesothelioma pathway for GP referrals, 
separate from the lung cancer pathway, to ensure rapid referral to a pleural service. Patient experience might also be improved through better signposting to clinical nurse specialists across the three UK countries.

\section{CONCLUSION}

The study provides new insights into gender differences in mesothelioma regarding time from symptom onset to diagnosis and patients' experiences. The care of patients with mesothelioma can be improved-and gender differences can be reduced-by reviewing diagnostic processes, including occupational history taking and by reviewing the occupational risk of mesothelioma categorisation. It may be beneficial to raise awareness among healthcare professionals who are the first point of contact at first presentation of symptoms, such as GPs.

Contributors LC and LD collected the data. MS designed the study and carried out all analysis. MS wrote the paper. AT and SR contributed to the analysis and the write up of the paper. The corresponding author (MS) attests that all listed authors meet authorship criteria and that no others meeting the criteria have been omitted. MS is the author acting as guarantor.

Funding This project was funded by Mesothelioma UK as part of a portfolio of research conducted by the Mesothelioma UK Research Centre-Sheffield (MUKRCS). The MUKRC-S is an alliance between the Mesothelioma UK and the University of Sheffield.

Disclaimer The views expressed are those of the author(s), and not necessarily those of Mesothelioma UK or University of Sheffield.

\section{Competing interests None declared.}

Patient consent for publication Consent obtained directly from patient(s)

Ethics approval This study involves human participants, but the University of Sheffield Ethics committee exempted this study because the data set did not include any personal or patient identifiable data.

Provenance and peer review Not commissioned; externally peer reviewed.

Data availability statement Data are available on reasonable request.

Supplemental material This content has been supplied by the author(s). It has not been vetted by BMJ Publishing Group Limited (BMJ) and may not have been peer-reviewed. Any opinions or recommendations discussed are solely those of the author(s) and are not endorsed by BMJ. BMJ disclaims all liability and responsibility arising from any reliance placed on the content. Where the content includes any translated material, BMJ does not warrant the accuracy and reliability of the translations (including but not limited to local regulations, clinical guidelines, terminology, drug names and drug dosages), and is not responsible for any error and/or omissions arising from translation and adaptation or otherwise.
Open access This is an open access article distributed in accordance with the Creative Commons Attribution Non Commercial (CC BY-NC 4.0) license, which permits others to distribute, remix, adapt, build upon this work non-commercially, and license their derivative works on different terms, provided the original work is properly cited, appropriate credit is given, any changes made indicated, and the use is non-commercial. See: http://creativecommons.org/licenses/by-nc/4.0/.

\section{REFERENCES}

1 Bibby AC, Tsim S, Kanellakis N, et al. Malignant pleural mesothelioma: an update on investigation, diagnosis and treatment. Eur Respir Rev 2016;25:472-86.

2 Cancer Research UK. Cancer research UK cancer incidence statistics. CancerResearchUK, 2018.

3 PH S. Cytoreductive surgery and perioperative chemotherapy for peritoneal surface malignancy: textbook and video atlas. Cine-Med Publishers Woodbury, 2012.

4 McElvenny DM, Darnton AJ, Price MJ, et al. Mesothelioma mortality in Great Britain from 1968 to 2001. Occup Med 2005;55:79-87.

5 Physicians RC of. National mesothelioma audit report.

6 Rake C, Gilham C, Hatch J, et al. Occupational, domestic and environmental mesothelioma risks in the British population: a casecontrol study. Br J Cancer 2009;100:1175-83.

7 Taioli E, Wolf AS, Camacho-Rivera M, et al. Women with malignant pleural mesothelioma have a threefold better survival rate than men. Ann Thorac Surg 2014;98:1020-4.

8 Stahel R, Bosco EF, Opitz I. Mesothelioma. In: Lung cancer therapy annual, 2008.

9 Ball H, Moore S, Leary A. A systematic literature review comparing the psychological care needs of patients with mesothelioma and advanced lung cancer. Eur J Oncol Nurs 2016;25:62-7.

10 Taylor BH, Warnock C, Tod A. Communication of a mesothelioma diagnosis: developing recommendations to improve the patient experience. BMJ Open Respir Res 2019;6:e000413.

11 Warby A, Dhillon HM, Kao S, et al. Managing malignant pleural mesothelioma: experience and perceptions of health care professionals caring for people with mesothelioma. Support Care Cancer 2019;27:3509-19.

12 Senek M, Steve Robertson AT. Mesothelioma: exploring gender differences in time to diagnosis, seeking legal advice and occupational risk. Cancer Nurs Pract 2020.

13 Arber A, Spencer L. 'It's all bad news': the first 3 months following a diagnosis of malignant pleural mesothelioma. Psychooncology 2013;22:1528-33.

14 Ejegi-Memeh S, Robertson S, Taylor B, et al. Gender and the experiences of living with mesothelioma: a thematic analysis. Eur $J$ Oncol Nurs 2021;52:101966.

15 Marinaccio A, Gariazzo C, Di Marzio D, et al. Predictors of filing claims and receiving compensation in malignant mesothelioma patients. Health Policy 2020;124:1032-40.

16 Morrin M, Jack Aldane HK. Don't breathe in: Bridging the Asbestos Safety Gap [Internet], 2019. Available: https://www.respublica.org. uk/wp-content/uploads/2019/11/Asbestos-Report-Final.pdf 